\title{
POTENCIALIDADES E PROBLEMAS AMBIENTAIS ASSOCIADOS AO TURISMO NO FERVEDOURO DO MUMBUCA, REGIÃO DO JALAPÃO, TO
}

\author{
Núbia Nogueira do Nascimento ${ }^{1}$ \\ Guilherme Pereira de Carvalho ${ }^{2}$ \\ Rosane Balsan $^{3}$
}

\section{Resumo}

Este artigo é resultado do trabalho de campo realizado no Parque Estadual do Jalapão no município de Mateiros, localizado no leste do Estado do Tocantins e que faz divisa com três estados brasileiros: Bahia, Maranhão e Piauí. O estudo avaliou alguns problemas ambientais decorrentes do turismo em três locais atrativos: as Dunas do Jalapão, a comunidade Quilombola Mumbuca e o Fervedouro do Mumbuca. Este último apresentou maior índice de problemas ambientais, particularmente no tocante ao despejo de lixo em trilhas e áreas de visitação. Também foi observada a carência de infraestrutura e de políticas públicas adequadas para desenvolvimento do turismo responsável, garantindo-se a preservação dos atributios naturais da região do Jalapão. O levantamento aqui apresentado torna-se subsídio importante à medida que trata sobre a preservação ambiental do Fervedouro, bem como discutir ações das políticas públicas para que os próximos turistas e a comunidade local possam usurfruir do turismo e ecoturismo local.

Palavras-chave: Jalapão; Fervedouro do Mumbuca; turismo; problemas ambientais

\begin{abstract}
This article is the result of fieldwork conducted in Jalapão State Park in the municipality of Bushmen, located in the eastern state of Tocantins and which borders three Brazilian states: Bahia, Maranhão and Piauí. The study evaluated some environmental problems of tourism in three attractive locations: the Dunes of Jalapão, the community of Quilombo Mumbuca Fervedouro of Mumbuca. The latter locality presented a higher environmental problems, particularly with regard to the dumping of garbage on trails and visitation areas. We noted the lack of infrastructure and appropriate public policies for responsible tourism development, ensuring the preservation of the region's natural features of Jalapão. The survey becomes important as grant comes on the environmental preservation of the Fervedouro and discuss actions of public policies for the next tourists and the local community can take benefits of tourism and ecotourism.
\end{abstract}

Keywords: Jalapão; Fervedouro do Mumbuca tourism; environmental problems

\section{Introdução}

O Estado do Tocantins conta atualmente com 13 Unidades de Conservação (UCs) Estaduais, sendo quatro de Proteção Integral e nove de Uso Sustentável (TOCANTINS,

\footnotetext{
${ }^{1}$ Mestranda em Geografia - UFT, Bacharel em Biblioteconomia - UFG. E-mail: nascimento.nubia@hotmail.com

${ }^{2}$ Mestrando em Geografia - UFT, Graduado em Geografia - UFT. E-mail: gpcgeo@ hotmail.com

${ }^{3}$ Dra. em Geografia UNESP, Professoa Adjunta da Universidade Federal do Tocantins - UFT - Campus de Porto Nacional. E-mail: rosanebalsan@ @otmail.com
} 
2013b). Uma dessas unidades é o Parque Estadual do Jalapão (PEJ), localizado no extremo leste do estado do Tocantins, fazendo divisa com os estados da Bahia, Maranhão e Piauí, na chapada das Mangabeiras (VON BEHR, 2004). O PEJ foi criado pela Lei Estadual 1.203 de 12/01/2001, com uma área de 158.000 hectares $\left(1.580 \mathrm{Km}^{2}\right)$ em área nuclear da região do Jalapão. Como se trata de uma UC de proteção integral, tem por objetivo a preservação dos recursos naturais da região admitindo-se, apenas, o aproveitamento indireto de seus recursos (TOCANTINS, 2013b).

A microrregião do Jalapão, onde está inserido o PEJ, é uma área de características distintas e peculiares dentro do Estado do Tocantins. A microrregião ocupa uma área de 53,3 mil $\mathrm{km}^{2}$, sendo que $34,1 \mathrm{mil} \mathrm{km}^{2}$ encontram-se dentro do Estado do Tocantins. As paisagens locais possuem inúmeras potencialidades naturais, porém demonstram uma série de fragilidades em relação ao solo, requerendo ações e/ou projetos voltados à preservação dos recursos naturais. O município de Mateiros (TO), por exemplo, é referência na produção do artesanato do capim dourado, onde está localizada a comunidade Mumbuca ${ }^{4}$, composta por descendentes de quilombolas.

Conforme a Figura 01, foram visitados três atrativos turísticos dentro do Parque Estadual do Jalapão: as Dunas do Jalapão, a Comunidade Quilombola Mumbuca e o Fervedouro do Mumbuca. O trabalho tem como finalidade relatar os principais problemas causados no atrativo turístico do Fervedouro, haja vista que foi constatado maior nível de degradação ambiental nesta área.

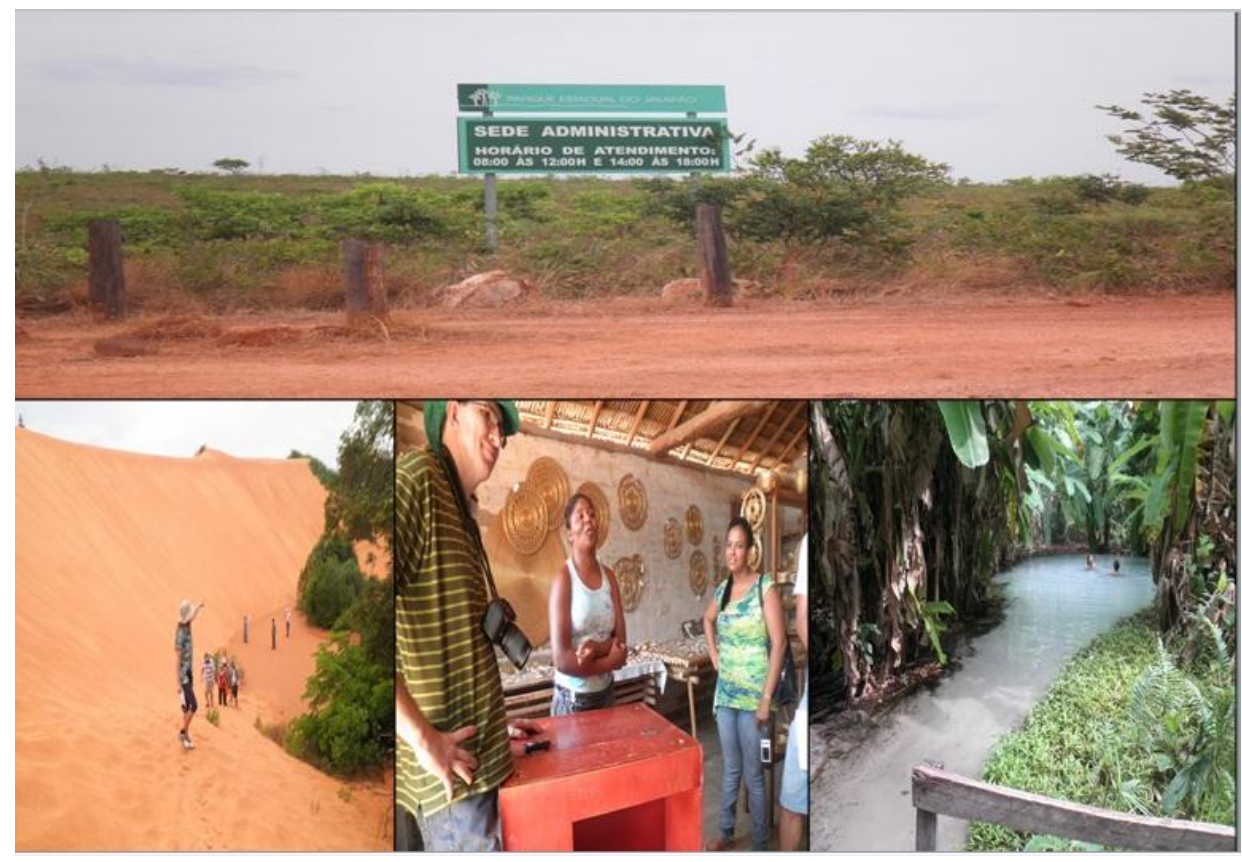

Figura01. Imagens dos três atrativos visitados no PEJ. Fonte: Nascimento (2012).

\footnotetext{
${ }^{4}$ Mumbuca, vila formada por uma maioria de descendentes de escravos, onde surgiu o tão popular artesanato em capim dourado. A vila está inserida no Parque Estadual do Jalapão (TOCANTINS, 2013a).
} 


\section{Características fisicas e ambientais da Região do Jalapão}

A região do Jalapão divide-se em duas unidades geomorfológicas: aos Patamares Leste do Tocantins e o Planalto Residual do Tocantins, sendo que o PEJ está localizado integralmente na unidade geomorfológica Patamares Leste do Tocantins (MENDES, 2008, p.12). As rochas que compreendem a região do PEJ se formaram por volta de 135 milhões de anos, quando houve a deposição dos arenitos da formação Urucuia, num ambiente essencialmente desértico (MENDES, 2008, p.7).

A região reúne quatro tipos de paisagens: o platô com chapadões e planaltos; as encostas onde estão posicionadas as nascentes dos rios; e as dunas resultantes da ação dos ventos. Quanto à Geologia, o Jalapão se caracteriza por uma área de rochas de arenito muito frágeis, sujeita a erosão provocada pelos ventos e chuvas, formando depósitos de areias. As águas das chuvas penetram facilmente na areia formando enormes aquíferos subterrâneos como os fervedouros (VON BEHR, 2004, p. 132). Nos platôs dos chapadões e planaltos observam-se serras tipos mesa e morros - testemunhos - ambientes estáveis e com vulnerabilidade ambiental baixa (VON BEHR, 2004, p. 138).

O Jalapão integra a bacia hidrográfica do Tocantins, com um imenso manancial de rios e córregos permanentes, favorecendo ainda mais a biodiversidade. As águas superficiais recobrem o Jalapão de arenitos. Há uma grande permeabilidade, devido o terreno arenoso, a água passa facilmente entre os poros dos terrenos impedindo a sua concentração na superfície e toda a água precipitada tende a se filtrar, até ressurgir lentamente, geralmente na base das escarpas, como fontes permanentes que formam as nascentes fluviais (VON BEHR, 2004, p. 148).

O clima da região é do tipo tropical-continental com duas estações bem definidas, uma "chuvosa" entre outubro e abril e outra mais seca entre setembro e maio. Segundo Santos (2008), a média anual de precipitação é de $1555 \mathrm{~mm}$ distribuídos, predominantemente, ao longo de sete meses (outubro/abril), mas é possível a ocorrência de chuvas esporádicas em maio e setembro. A temperatura média anual é de $30^{\circ} \mathrm{C}$, passando dos $35^{\circ} \mathrm{C}$ durante o dia e caindo para $18^{\circ} \mathrm{C}$, ou menos, durante a noite.

Existem três grandes domínios morfoclimáticos na região: as depressões recobertas por caatingas - leste nordeste; os chapadões recobertos por cerrados, penetrados por florestas galerias - sul-sudeste; e as terras baixas florestadas da Amazônia - noroeste.

A cobertura vegetal é na grande maioria de fisionomia aberta. É composta, basicamente, de cerrado (cerrado stricto sensu ou cerrado denso) e campos, dominados por herbáceas, caracterizadas por gramíneas, arvoretas e plantas lenhosas baixas. Em menor proporção ocorre também o cerradão, a mata ciliar (ao longo dos córregos e rios) e a de galeria (igualmente ao longo dos córregos e dos rios, porém fechada em cima, formando as galerias). Os campos e os cerrados são mais comuns nos platôs e rebordos da chapada, na área de sopé das serras e montanhas e em outras áreas planas. A vegetação possui padrão savânico de cerrado. 
Para Santos (2008, p.55-56) "o cerrado sentido restrito presente na região pode ser caracterizado pela presença de árvores baixas, inclinadas, tortuosas com ramificações irregulares e retorcidas e geralmente com evidencias de queimadas". Os arbustos e subarbustos encontram-se espalhados com algumas espécies apresentando órgãos subterrâneos perenes (xilopódios) que permitem a rebrota após queima ou corte. Na época chuvosa os estratos subarbustivo e herbáceo tornam-se exuberantes devido ao seu rápido crescimento. Os troncos das plantas lenhosas possuem em geral, casca com cortiça grossa, fendada ou sulcada, e as gemas apicais de muitas espécies são protegidas por densa pilosidade. As folhas são geralmente rígidas e coriáceas, fornecendo adaptação condições de seca (xeromorfismo).

Nas áreas planas e baixas a vegetação do cerrado é relativamente aberta. Nas veredas, ou seja, áreas úmidas e sujeitas às inundações, geralmente são ocupadas com palmeiras de buritis (VON BEHR, 2004, p. 132). Ainda conservada, a região tem grande possibilidades de ser uma área transição entre a caatinga e o cerrado. A vegetação de campos e cerrados de fisionomia aberta é muito rica, assim como a fauna (VON BEHR, 2004, p. 133).

Devido à tendência da crescente de influência humana, o Jalapão tem sofrido intensificação dos processos erosivos, principalmente em função da fragilidade vegetal e das características do solo, potencializando processos de desertificação na área (VON BEHR, 2004, p. 170). Tal situação, aliada à necessidade de conservação, levou os governos federal e estadual a criar cinco UCs que se destinam a proteger legalmente o cerrado. O governo estadual criou as seguintes UCs: Área de Proteção Ambiental (APA) Estadual do Jalapão, Parque Estadual do Jalapão. O governo federal, na figura do ICMBio mantém a Estação Ecológica da Serra Geral do Tocantins (TO e BA); o Parque Nacional das Nascentes do Rio Parnaíba (TO, BA, PI e MA); e a Área de Proteção Ambiental da Serra da Tabatinga (extremo leste do TO e PI), segundo Von Behr (2004, p. 170).

\section{Unidades de Conservação Estaduais da Região do Jalapão}

As UCs estaduais são duas: APA do Jalapão e o PE do Jalapão, sendo a primeira de uso sustentável e a segunda de proteção integral. A APA foi criada em junho de 2000, pela Lei n. 1.172, com 461.730 hectares ocupando terras de três municípios: Mateiros, Novo Acordo e Ponte Alta do Tocantins. Ela funciona como zona de amortecimento para o PE do Jalapão e propicia a ligação do parque, ao sul, com a Estação Ecológica da Serra Geral do Tocantins, e a oeste com o Parque Nacional das Nascentes do Rio Parnaíba. Por sua localização estratégica faz parte do Corredor Ecológico Jalapão / Mangabeiras. Registra em seus limites a presença de espécies ameaçadas de extinção, como o Lobo-Guará (Chrysocyon brachyurus), arara-azul-grande (Anodorhyncus hyacinthinus) e o pato-mergulhão (Mergus octosetaceus), uma das aves mais ameaçadas das Américas. (TOCANTINS, 2013c).

Assim, a proposta da APA Jalapão aparece como fator de proteção do patrimônio mineral, biológico e cultural notório por seus aspectos físicos, paisagísticos e de biodiversidade promovendo a conservação e a melhoria das condições de vida da população 
local (TOCANTINS, 2003c). O fervedouro ${ }^{5}$ do Mumbuca, atrativo objeto deste estudo, fica localizado na APA, sendo um local muito procurado por visitantes. Entretanto, não foi detectado nenhum tipo de iniciativa para a conservação do atrativo, havendo riscos ambientais em função do uso intenso e desordenado.

Vale enfatizar que, de acordo com o Ministério de Meio Ambiente (2013, p. 1). A grande maioria dos usos e da exploração de recursos naturais permitidos nas UCs brasileiras prevê atividades que contribuam para a geração de renda, emprego, aumento da qualidade de vida e o desenvolvimento, sem prejuízo à conservação ambiental. Entretanto, as políticas públicas governamentais deveriam se preocupar mais com a conservação dos recursos naturais desse local.

O PEJ é uma área de proteção integral localizada no Município de Mateiros (Figura 02). Com uma população de 2.223 habitantes, tem uma das menores densidades demográficas do Tocantins, ou seja, 0,23 habitantes por $\mathrm{km}^{2}$. O PEJ , em seus 158.000 hectares, apresenta um dos conjuntos naturais mais interessantes do Estado do Tocantins, com formações rochosas resultantes de depósitos marinhos de bilhões de anos (TOCANTINS, 2013).

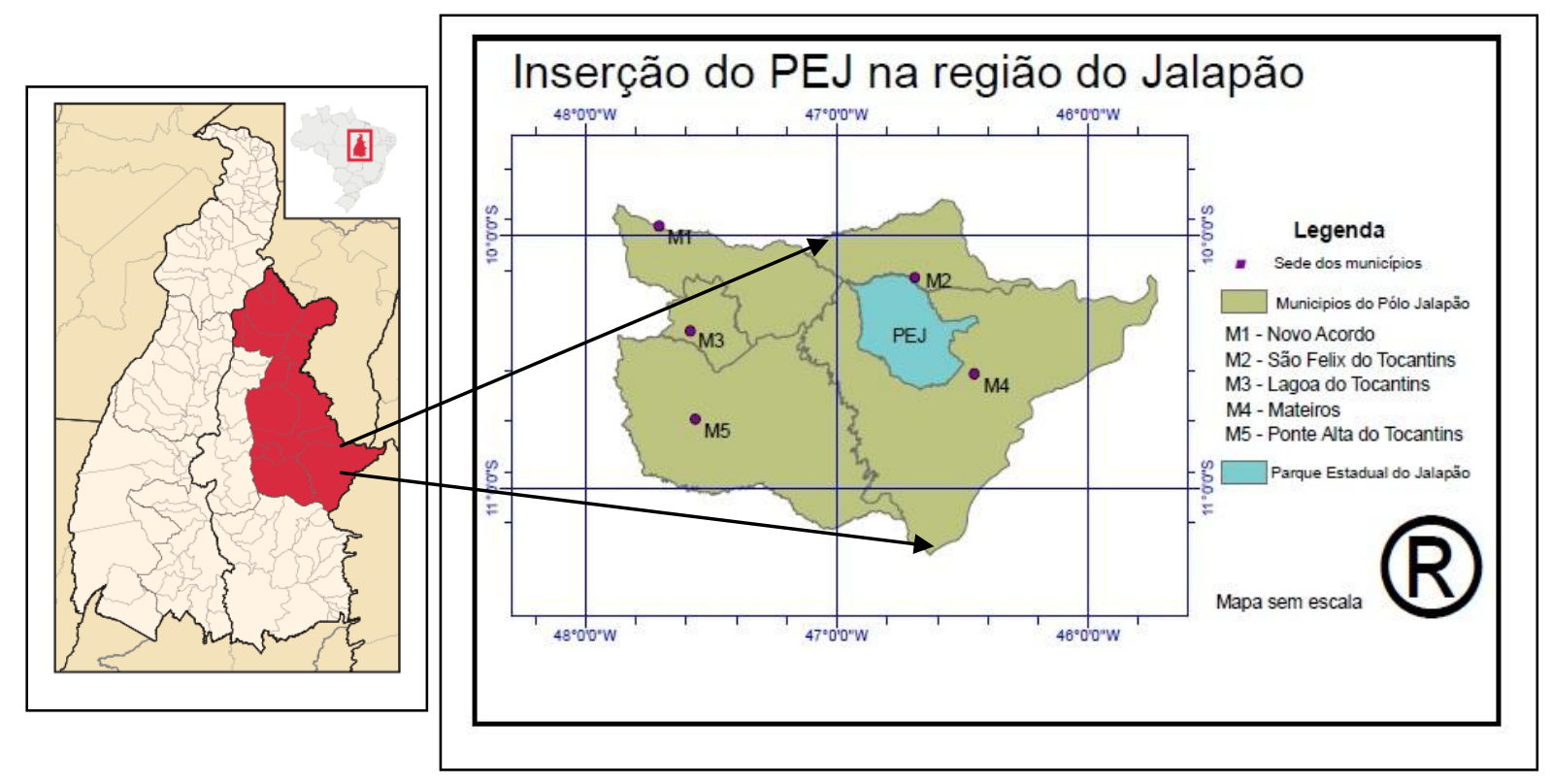

Figura 02. Localização da microrregião do Jalapão e inserção do PEJ (sem escala). Fonte: Adorno (2008).

O PEJ é o maior parque do estado e ocupa posição é estratégica como elo de ligação entre as áreas protegidas da APA do Jalapão, Estação Ecológica da Serra Geral e Parque Nacional das Nascentes do Parnaíba, integrando um mosaico de UCs que proporciona a manutenção do fluxo genético das populações silvestres. Essa característica é um dos

\footnotetext{
${ }^{5}$ Nascente de águas cristalinas formando um poço com aproximadamente 6 metros de diâmetro onde afloram as águas em meio a areias extremamente finas. Gases emergem nas águas impedindo que as pessoas afundem, um fenômeno chamado "ressurgência da água" (TOCANTINS, 2013c).
} 
principais atributos do parque, na medida em que garante a manutenção da biodiversidade dessa extensa área ainda conservada.

\section{Problemas associados ao turismo nas UCs do Jalapão}

O Parque Estadual do Jalapão (PEJ) é cada vez mais conhecido pelos turistas por possuir locais de grande beleza cênica, incluindo as paisagens de cerrado, as veredas com a presença do capim dourado e de alguns animais ameaçados de extinção, como o lobo-guará e a arara-azul. Neste sentido, pode-se mencionar a prática do turismo e do ecoturismo que crescem cada vez mais aumentando o número de visitantes que se deslocam para conhecer as paisagens e os atrativos locais. Entretanto, o potencial turístico local e regional não é acompanhado por uma infraestrutura adequada. A cidade de Mateiros é de pequeno porte e de difícil acesso com estradas não pavimentadas, dificultando o fluxo de turistas. Existem poucas opções de restaurantes e de hotéis, além da inexistência de agências turísticas locais, etc. Além disso, as pessoas diretamente envolvidas com o trabalho turístico, possuem pouca qualificação nesta área. A maioria das pessoas envolvidas neste trabalho são da própria comunidade e precisam desta renda para o próprio sustento.

O ecoturismo no contexto de um conjunto de práticas e conceitos variados, vem ganhando adeptos, não somente entre os leigos, mais principalmente entre os que atuam e se preocupam, efetivamente, com o planejamento e a gestão dessa modalidade de turismo e com a sua correta implementação (IRVING, 2008). Segundo Ruschmann (2001) estima-se que a implementação de atividades de ecoturismo possa trazer impactos positivos gerando empregos para a população local.

No Fervedouro do Mumbuca pode-se notar que a prestação de serviços junto aos turistas é feita por membros da própria comunidade, o que é positivo para a população, entretanto são necessários maiores investimentos para a qualificação desta mão de obra. Desse modo o adequado planejamento turístico pode estabelecer condições favoráveis para se alcançar os objetivos propostos. Tem por objetivo o aprovisionamento de facilidades e serviços para que a comunidade atenda seus desejos e necessidades, ou seja, o "desenvolvimento de estratégias que permitam a uma organização comercial visualizar oportunidades de lucros em determinados segmentos de mercados" (HARRY; SPINK, 1990, p. 33, apud RUSCHMANN, 1997, p. 83).

No PEJ foram feitas pesquisas exploratórias em campo acompanhadas por documentação fotográfica. A Figura 03 fornece uma amostra dos problemas identificados nos acessos e áreas de visitação. 


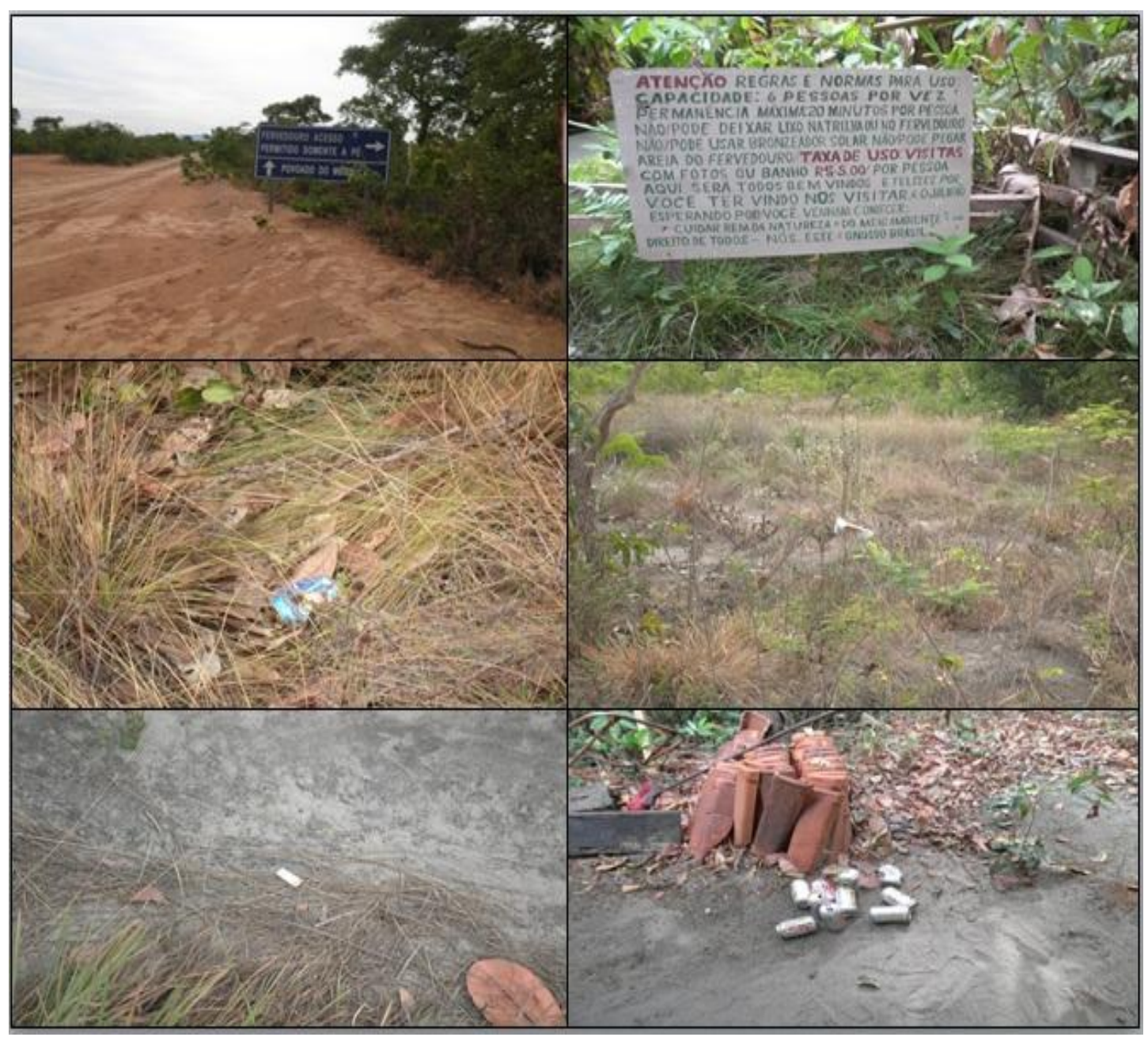

Figura 03. Despejo de resíduos sólidos no Fervedouro do Mumbuca Fonte: (NASCIMENTO, 2012)

Entre os problemas mais comuns documentados, destaca-se a presença de resíduos sólidos (embalagens de balas, cigarros, latas de alumínio, entre outros) em trilhas e no meio da vegetação, inclusive as escórias de obras. Também foi observada a deficiência de sinalização e orientação com placas apropriadas.

Segundo Vieira et. al. (2000), as áreas de uso público das UCs foram planejadas para atender a uma demanda menor do que a atual, com atividades menos impactantes e com um público muito diferente daquele que atualmente frequenta essas áreas protegidas. Para conciliar o uso recreativo dessas áreas com seus objetivos primários, por exemplo, a conservação dos recursos naturais e a pesquisa científica, os locais designados para o desenvolvimento de atividades de uso público devem ser manejados para controlar os efeitos negativos sobre o ambiente e garantir a qualidade da experiência do visitante.

\section{Conclusões}

As áreas da região do Jalapão se caracterizam por grande riquezea de paisagens naturais que proporcionam um grande potencial de visitação e desenvolvimento econômico 
baseado no turismo e ecoturismo. Entretanto, ainda existem grandes deficiências de infraestrutura local para promover o turismo de forma responsável com baixo impacto ambiental e sobre a biodiversidade.

As visitas realizadas na área possibilitaram avaliar a grande potencialidade do Fervedouro do Mumbuca para desenvolvimento do turismo, entretanto, a falta de planejamento adequado e de programas de capacitação dos moradores locais na prestação de serviços turísticos ainda é uma barreira a ser transposta. Com a pesquisa foi verificada a necessidade de mais incentivos da prefeitura local e do governo estadual. Há necessidade de mais investimentos em publicidade e propaganda sobre as atratividades oferecidas no Jalapão e em seu entorno, utilizando-se os meios disponíveis (cartazes, planfetos, televisão e/ou rádio) e acompanhado por ações educativas. Vale salientar que os problemas ambientais encontrados no Fervedouro podem ter sido causados pelos turistas, mas a população local também pode ter tido responsabilidade no despejo de lixo em locais de preservação.

No geral, vale ressaltar ainda a importância que a pesquisa acadêmica tem como forma de informação sobre a preservação, tanto para a comunidade local como no comportamento dos turistas. Existe a necessidade imperiosa para que os governos promovam o planejamento e a gestão do Parque Estadual do Jalapão. Assim, esta pesquisa traz também em seu contexto uma discussão dos significados e dos espaços estudados pela ciência geográfica.

Assim, Cavalcanti (1998) diz que não basta aos que se dedicam à docência e a investigação de questões relacionada com o saber Geográfico, o domínio de conteúdos e métodos da ciência geográfica. É preciso que se considere, além disso, a relação entre a ciência e sua organização para o ensino, incluindo aí a aprendizagem.

\section{Referências bibliográficas}

ADORNO, L. F. M. Relatório técnico conclusivo: turismo no Parque Estadual do Jalapão; identificação dos usos e proposição de medidas de controle e monitoramento. 2008.

BRASIL. Ministério do Meio Ambiente. Usos Permitidos. Disponível em: <http://www.mma.gov.br/areas-protegidas/unidades-de-conservacao/usos-permitidos>. Acesso em: 19 maio 2013.

CAVALCANTI, L. S. Geografia, escola e construção de conhecimentos. 6. ed. Campinas: Papirus, 1998.

IRVING, M. A. Ecoturismo em áreas protegidas: da natureza ao fenômeno social. In: COSTA,Nadja Maria Castilho da; NEIMAN, Zysman; COSTA, Vivian Castilho da (Org.). Pelas trilhas do ecoturismo. São Carlos: Rima, 2008. p. 1-15.

MENDES, L. R. Aplicação de técnicas de geoprocessamento para análise geomorfológica do Parque Estadual do Jalapão (TO) e seu entorno. 2008.78 f. Dissertação (Mestrado em Geografia)- Pós-gradução em Geografia, Universidade de Brasília, Brasília, 2008.

RUSCHMANN, D. Van de M. (Coord.). Diagnóstico e análise preliminar do potencial ecoturístico da região do Bico do Papagaio. Palmas: Secretaria do Planejamento e Meio Ambiente (SEPLAN); Diretoria de Meio Ambiente e Recursos Hidríco (DMA), 2001. 
Turismo e planejamento sustentável: a proteção do meio ambiente.

Campinas, SP: Papirus, 1997. (Coleção turismo).

SANTOS, P. A. dos. A utilização das geotecnologias para o mapeamento e analise multitemporal da cobertura vegetal do Parque Estadual do Jalapão (PEJ) - Tocantins. 2008. 155 f. Dissertação (Mestrado em Ciências do Ambiente) - Universidade Federal do Tocantins, Palmas, 2008.

TOCANTINS. Áreas protegidas do Tocantins. Disponível em:

<http://areasprotegidas.to.gov.br/conteudo.php?id=6>. Acesso em: 3 abr. 2013.

Jalapão: Tocantins. Disponível em: <http://jalapao.to.gov.br/localizacao/73> . Acesso em: 5 abr. 2013a.

Parque Estadual do Jalapão. Disponível em: 〈http://www.gesto.to.gov.br/uc/45/>. Acesso em: 4 abr. 2013b. SECRETARIA DO PLANEJAMENTO E MEIO AMBIENTE( SEPLAN). Plano de Manejo do Parque Estadual do Jalapão. Palmas: 2004, 219 p. Disponível em: < http://sinat.naturatins.to.gov.br/site/unidades_conservacao/docs/jalapao/pej_encarte_planejam ento.pdf >. Acesso em: 20 maio 2013c.

VIEIRA, V. M. M.; PASSOLD, A. J.; MAGRO, T. C. Impactos do uso público: um guia de campo para utilização do método VIM. In: CONGRESSO FLORESTAL BRASILEIRO DE UNIDADES DE CONSERVAÇÃO, 2., 2000, Campo Grande. Anais... Campo Grande, Rede Nacional Pró-Unidades de Conservação. v. 1, p. 296-305, 2000.

VON BEHR, M. Jalapão: sertão das águas. São José dos Campos, SP: Somos Editora, 2004. 